\title{
ANÁLISE DE MANIFESTAÇÖES PATOLOGICAS NA BALAUSTRADA DA AV. GETÚLIO VARGAS EM NATAL/RN: UM ESTUDO DE CASO
}

\author{
QUEIROZ, ANNA BEATRIZ RODRIGUES DE \\ Graduanda em Engenharia Civil \\ Universidade Potiguar \\ Rio Grande do Norte; Brasil \\ beatriz.abrq@hotmail.com \\ MARQUES, MARCOS VINÍCIUS DIAS \\ Graduando em Engenharia Civil \\ Universidade Potiguar \\ Rio Grande do Norte; Brasil \\ mv.vinicius2000@gmail.com
}

CRUZ, CLÁUDIA PATRÍCIA TORRES

Professora Doutora em Física da Matéria Condensada

Universidade Potiguar

Rio Grande do Norte; Brasil

claudiacruz.unp@gmail.com

\author{
SANTOS, KLLEYSON FREITAS DOS \\ Graduando em Engenharia Civil \\ Universidade Potiguar \\ Rio Grande do Norte; Brasil \\ klleysonfreitas2@hotmail.com
}

\author{
SANTOS, RODRIGO RODRIGUES DOS \\ Graduando em Engenharia Civil \\ Universidade Potiguar \\ Rio Grande do Norte; Brasil \\ rodrigorodrigues9798@ hotmail.com
}

\author{
LUCENA, MAURÍLIO DE MEDEIROS \\ Professor Mestre em Engenharia Mecânica \\ Universidade Potiguar \\ Rio Grande do Norte; Brasil \\ mauriliomedeiros@unp.br
}

\section{RESUMO}

A inobservância de planos de manutenção corretiva e preventiva geram a degradação dos elementos construtivos e o aparecimento ou agravamento de manifestações patológicas. Este trabalho tem como objetivo realizar um levantamento das manifestações patológicas em uma balaustrada situada na região litorânea de Natal-RN. Foi realizada "in loco" uma ampla inspeção visual com acervo fotográfico para a identificação das áreas com manifestações patológicas, em seguida foi verificado, através do ensaio de inspeção, o nível de carbonatação do concreto através da aplicação de solução química de fenolftaleína. Os resultados indicaram, através da baixa coloração que prevaleceu no concreto, níveis significativos de carbonatação na maioria das peças de concreto. A partir da análise das fissuras da estrutura, do desplacamento do concreto e da corrosão da armadura, recomenda-se que sejam adotadas medidas emergenciais para amenizar as degradações provocadas pela agressividade ambiental.

Palavras-chave: balaustrada, corrosão, durabilidade, estrutura.

\section{ABSTRACT}

Non-compliance with corrective and preventive maintenance plans leads to the degradation of building elements and the appearance or worsening of pathological manifestations. This work aims to carry out a survey of the pathological manifestations in a balustrade located in the coastal region of Natal-RN. An extensive visual inspection with a photographic collection was carried out "in loco" to identify the areas with pathological manifestations, then the level of carbonation of concrete was verified through the inspection test through the application of a chemical solution of phenolphthalein. The results indicated, through the low staining that prevailed in the concrete, significant levels of carbonation in most concrete parts. From the analysis of the structure cracks, concrete paving and reinforcement corrosion, it is recommended that emergency measures be taken to mitigate the degradation caused by environmental aggressiveness. Keywords: balustrade, corrosion, durability, structure. 


\section{INTRODUÇÃO}

O elevado número de patologias em elementos construtivos ocorre devido à falta de planos de manutenção ou devido à manutenção incorreta. Segundo Fialho (2009), a falta de manutenção, associada a outros fatores, traz a deterioração prematura das estruturas de concreto armado.

Em estruturas de concreto, a manutenção preventiva, assim como outros aspectos, é de extrema importância para garantir a integridade da peça. De acordo com Souza (1998), falhas nas etapas de execução e escolha dos materiais aparecem como as principais causas das patologias em estruturas de concreto. Para Farias (2019), a vida útil e durabilidade de uma estrutura estão relacionadas com a agressividade do ambiente que a estrutura está inserida.

De acordo com Kulakowski (2002), uma das ocorrências preponderantes com relação à deterioração da armadura é a despassivação por carbonatação, que consiste em uma interação físico-química onde produtos alcalinos presentes no concreto reagem com o gás carbônico presente na atmosfera. A carbonatação não causa dano direto à estrutura, porém o aumento da vulnerabilidade da armadura possibilita a ação de agente corrosivos (FIALHO, 2009). Os efeitos da carbonatação nas estruturas são diminuídos se medidas de controle da evolução das fissuras e de execução do cobrimento da armadura forem executados conforme a NBR 6118-2014. Outro fator de extrema relevância que é afetado pelo processo de carbonatação é o pH do concreto. Segundo Kulakowski (2002), uma região é classificada como não carbonatada se o $\mathrm{pH}$ for acima de 12; já a região carbonatada apresenta um pH abaixo de 9 . Além disso, tem-se a classe de agressividade ambiental que influencia diretamente na deterioração da estrutura. De acordo com a NBR 6118-2014, a agressividade do meio ambiente está relacionada às ações físicas e químicas que atuam sobre as estruturas de concreto, independentemente das ações mecânicas, das variações volumétricas de origem térmica, da retração hidráulica e outras previstas no dimensionamento das estruturas e estas podem ser classificadas como: fraca, moderada, forte ou muito forte.

O presente estudo tem como objetivo identificar e analisar as manifestações patológicas em uma balaustrada localizada na Avenida Getúlio Vargas na cidade de Natal/RN, bem como discutir as origens e possíveis causas dessas manifestações.

\section{METODOLOGIA}

O estudo foi realizado em uma balaustrada de concreto armado localizada na Avenida Getúlio Vargas em Natal/RN. A estrutura de concreto em estudo possui 24 metros de extensão, possuindo 26 balaústres. As dimensões, em centímetros, e representação dos balaústres podem ser observadas no croqui da Figura 1.
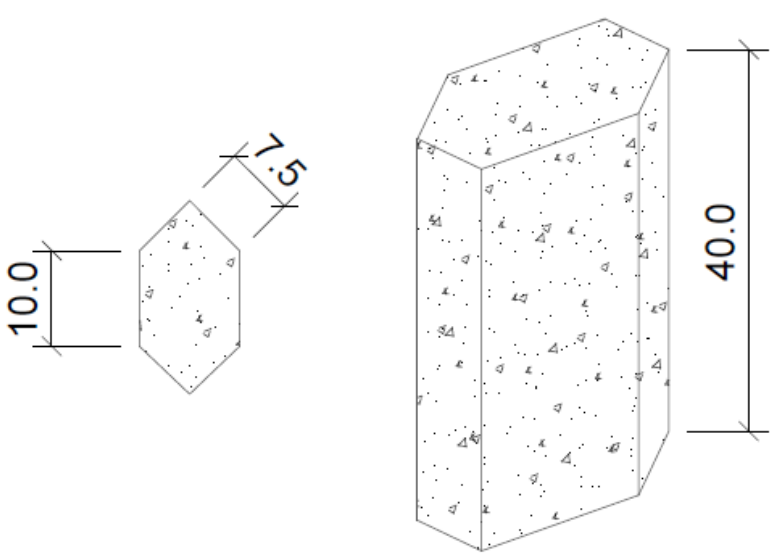

Figura 1: Croqui dos balaústres.

Fonte: Autores, 2019.

Quanto aos procedimentos metodológicos, o estudo dividiu-se em quatro fases. A primeira fase consistiu na revisão bibliográfica, onde foi realizada uma seleção de trabalhos relevantes acerca do tema. Na segunda fase, foi realizada uma visita in loco com o objetivo de fazer uma análise preliminar da estrutura e definir as condições de exposição da balaustrada. Em seguida, na terceira fase, realizou-se uma inspeção visual que consistiu em detectar as anomalias e fazer o registro fotográfico. Ainda nesta etapa, com o objetivo de verificar o nível de carbonatação do concreto, foi realizado um ensaio de inspeção utilizando a solução química de fenolftaleína. 
Por fim, na quarta fase, foi elaborado um levantamento qualitativo das principais manifestações patológicas presentes nas balaustradas e foram apresentados os fatores que, possivelmente, contribuíram/definiram as causas para o surgimento das manifestações patológicas. A Figura 2 ilustra um fluxograma com a metodologia utilizada para o processo de identificação das anomalias presentes na estrutura estudada.

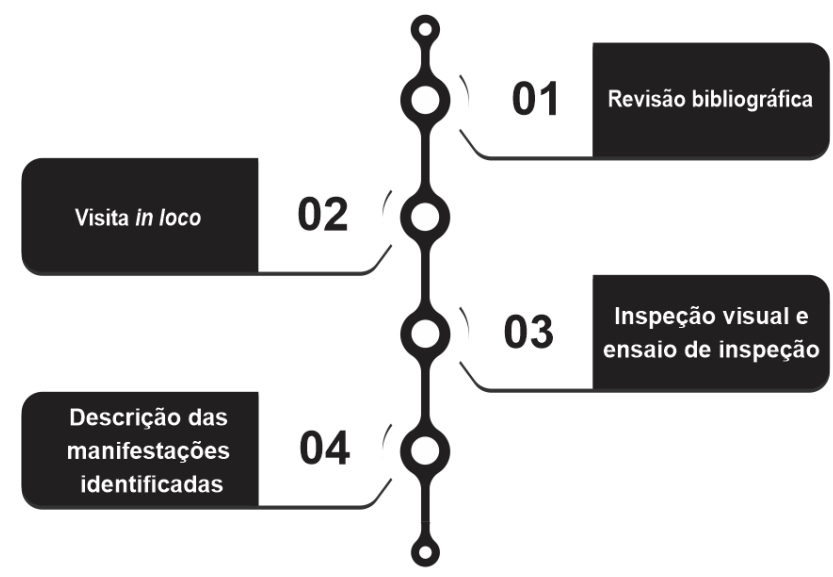

Figura 2: Fluxograma de procedimentos metodológicos Fonte: Autores, 2019.

\section{RESULTADOS E DISCUSSÕES}

$\mathrm{Na}$ visita in loco foram verificadas condições de exposição da estrutura que influenciaram diretamente no desgaste e surgimento de manifestações patológicas. O ambiente tem grande influência da maresia e apresenta intenso tráfego de veículos e, de acordo com a classificação da NBR 6118:2014, a estrutura situa-se em uma classe de agressividade ambiental III com forte agressividade e elevado risco de deterioração da estrutura. A partir disso, é evidente a existência de agressividade ambiental através de ataque químico no concreto que implica na durabilidade e qualidade da estrutura. A tabela de classificação de classes de agressividade ambiental da NBR 6118:2014 pode ser observada na Tabela 1.

Tabela 1: Classificação de classe de agressividade ambiental.

Fonte: Adaptado de ABNT, 2014.

\begin{tabular}{c|c|c|c}
\hline \multirow{2}{*}{$\begin{array}{c}\text { Classe de } \\
\text { agressividade } \\
\text { ambiental }\end{array}$} & Agressividade & $\begin{array}{c}\text { Classificação geral do tipo de } \\
\text { ambiente para efeito de projeto }\end{array}$ & $\begin{array}{c}\text { Risco de deterioração da } \\
\text { estrutura }\end{array}$ \\
\hline \multirow{2}{*}{ I } & \multirow{2}{*}{ Fraca } & Rural & \multirow{2}{*}{ Insignificante } \\
\cline { 3 - 3 } II & Moderada & Submersa & \multirow{2}{*}{ Pequeno } \\
\hline \multirow{2}{*}{ III } & \multirow{2}{*}{ Forte } & Urbana & \multirow{2}{*}{ Grande } \\
\cline { 3 - 3 } IV & \multirow{2}{*}{ Muito forte } & Marinha & Elevado \\
\cline { 3 - 3 } & & Industrial & Industrial \\
\hline
\end{tabular}

Após detectar grande influência da agressividade ambiental sobre a estrutura, a etapa de inspeção visual constatou grande deterioração das peças através de fissuras iniciais que chegam a atingir um elevado nível de desplacamento do concreto, corrosão das armaduras, anomalias exógenas, deterioração da pintura devido ao processo de corrosão e contaminação por fatores externos. 


\section{CBPAT 2020

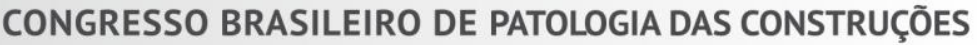 \\ DE 15 A 17 DE ABRIL | FORTALEZA - CE}

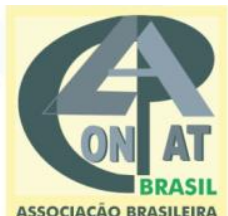

No ensaio de inspeção foram verificadas as condições da microestrutura do concreto realizando a aplicação de solução química de fenolftaleína como indicador químico para identificar se a peça estava carbonatada. Foi constatado, através da baixa coloração, que as peças de concreto se apresentavam carbonatadas, conforme ilustrado na Figura 3.

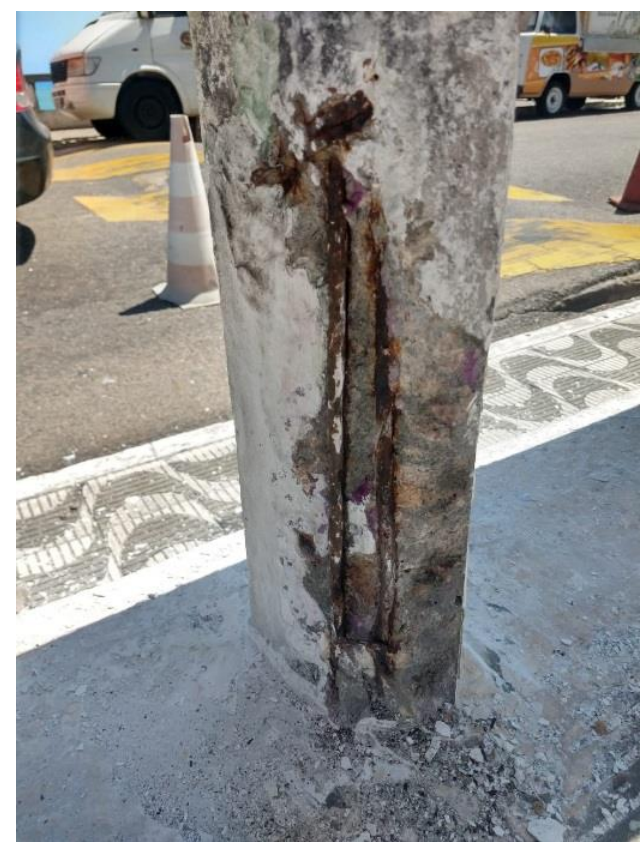

Figura 3: Ensaio de inspeção de fenolftaleína.

Fonte: Autores, 2019.

Através das aberturas das fissuras ocorre o ataque químico na microestrutura do concreto que pode gerar a despassivação da armadura, tornando o elemento estrutural vulnerável ao processo de corrosão. De acordo com Kulakowski (2002) a corrosão das armaduras pode ser desencadeada por meio de dois agentes principais, sendo eles a ação de íons cloreto, que altera a película passivadora, e a carbonatação, diminui a alcalinidade do concreto, reduzindo a estabilidade da película passivadora. A Figura 4 apresenta uma peça da balaustrada suscetível ao processo corrosivo.

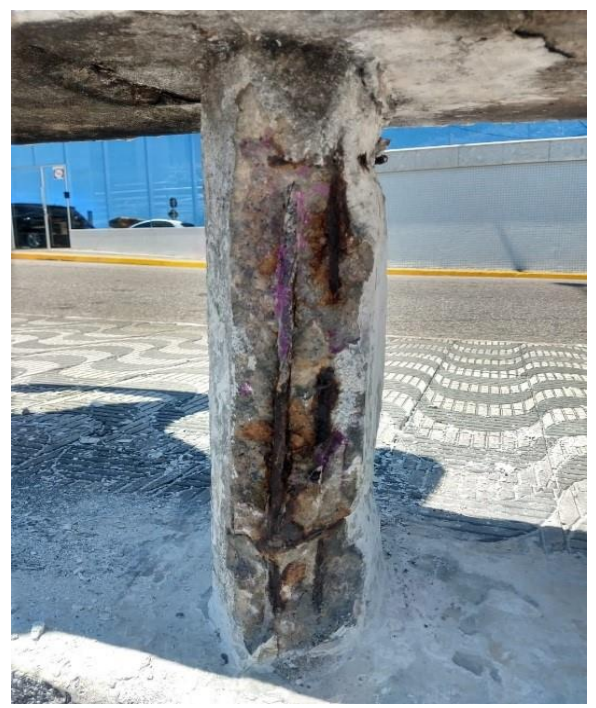

Figura 4: Armadura suscetível à corrosão. Fonte: Autores, 2019 
Ao longo da balaustrada verifica-se casos em que balaústres estão com a degradação quase que total da estrutura, apresentando a separação entre armadura e concreto. Segundo Andrade (1992), a situação apresentada na Figura 5 é caracterizada como caso de corrosão por cloretos, sendo observada a desagregação do concreto nas barras de aço da peça, que podem ter penetrado no concreto devido ao ambiente marinho, que é o ambiente em que se encontra a balaustrada.

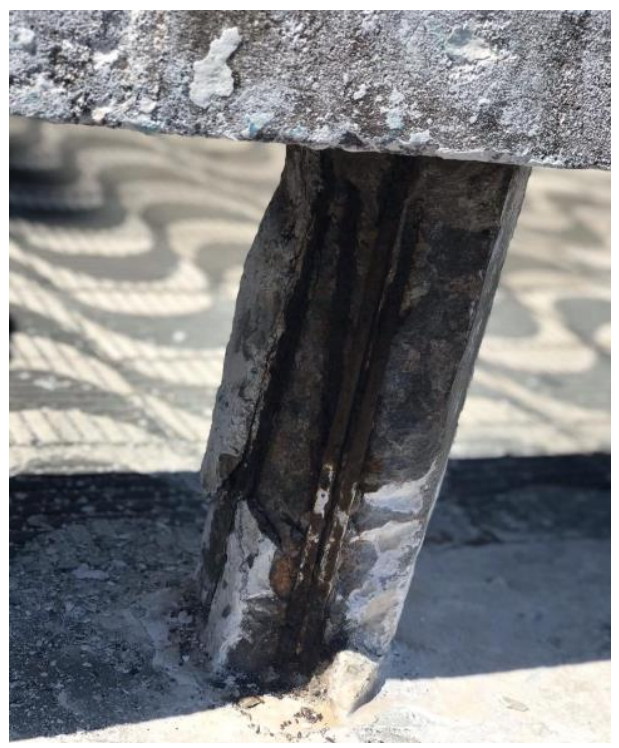

Figura 5: Desplacamento do concreto.

Fonte: Autores, 2019

Além de manifestações patológicas naturais, a intensidade de tráfego de veículos promoveu o surgimento de anomalias exógenas que provocaram a destruição das peças por colisão de veículos. A Figura 6 ilustra situação de destruição de parte da balaustrada decorrente de uma colisão de veículo.

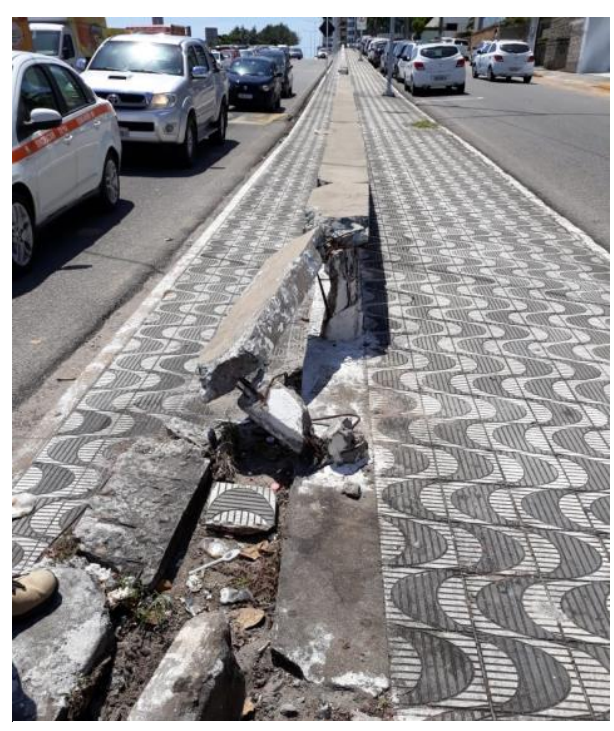

Figura 6: Anomalia exógena.

Fonte: Autores, 2019.

Outras manifestações patológicas identificadas estão relacionadas com a pintura presente na estrutura. Foram observadas manchas de coloração escura onde existe exposição da armadura com corrosão, que, para Helene (1992), pode estar relacionado com o produto gerado pela corrosão que tem predominância de coloração vermelho-marrom e pela solubilidade desse produto de corrosão que faz com que escorra na superfície do concreto conforme pode ser observada na Figura 7. Outras manchas indicam manifestação de eflorescência devido à alta umidade presente na estrutura e sobreposições de camadas de pinturas como pode ser visualizada na Figura 8. 


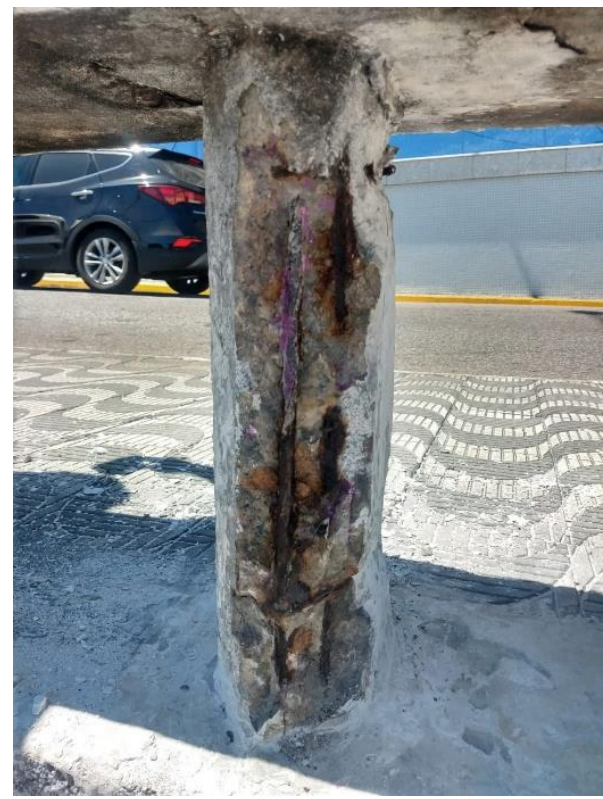

Figura 7: Manchas devido a corrosão da armadura. Fonte: Autores, 2019.

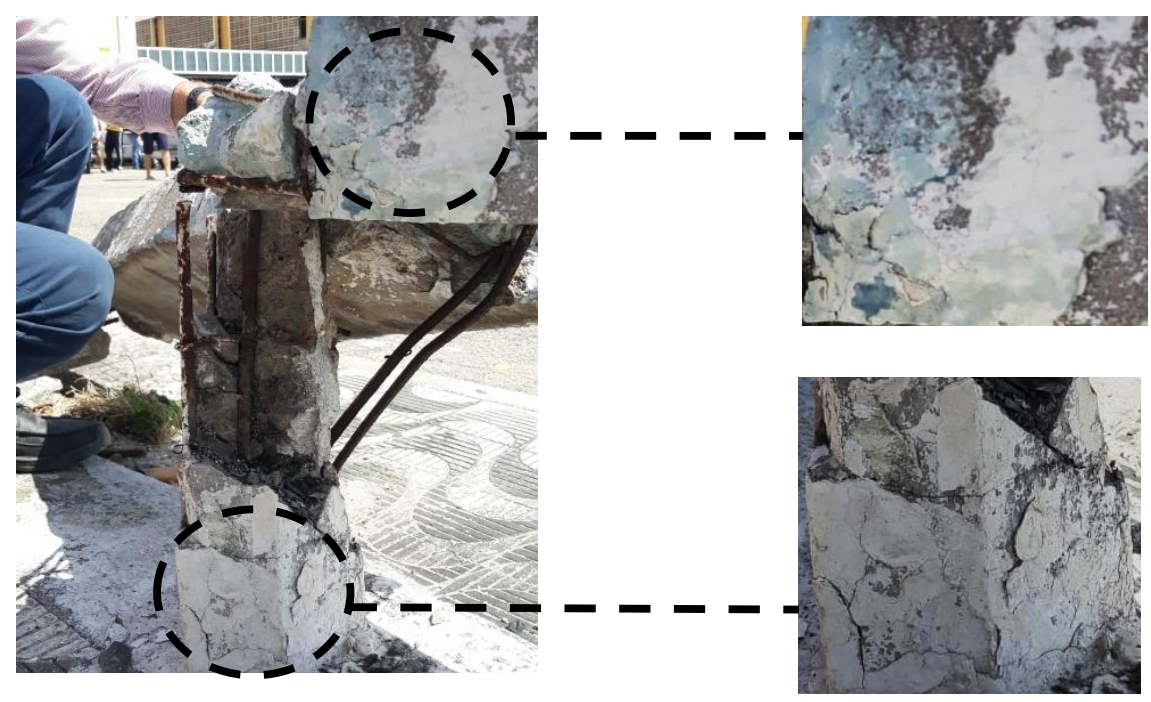

Figura 8: Anomalias na pintura. Fonte: Autores, 2019.

\section{CONCLUSÕES}

São diversas as causas do surgimento de manifestações patológicas e da consequente deterioração da balaustrada. Dentre essas causas, algumas destacam-se devido à importância e influência na durabilidade do material constituinte da estrutura e da própria estrutura em si.

A classe de agressividade ambiental fornece grande possibilidade para que o concreto da estrutura venha sofrer danos devido à contaminação por fatores externos, principalmente pela maresia presente no local. Para a situação existem duas formas de contaminação do concreto, que de acordo com os resultados do ensaio de inspeção por solução química de fenolftaleína, aponta que o concreto está contaminado por carbonatação, sendo ainda possível afirmar a incidência de cloretos nessa contaminação. Além disso, aspectos como cobrimento do concreto e permeabilidade influenciaram para que esses agentes externos tivessem maior profundidade de penetração. 
Mesmo com várias vertentes sobre a durabilidade da estrutura, sejam elas que contribuem ou comprometem, ainda assim é correto afirmar que a ausência de manutenção preventiva e até mesmo corretiva para as primeiras manifestações foi de extrema relevância para que a estrutura atingisse maior nível de degradação. Também se destaca falhas no serviço de execução no caso de a estrutura apresentar diversas camadas de pintura sobrepostas, que indica que novas demãos de tinta eram aplicadas sem a correta técnica ou processo executivo. Assim, é correto afirmar que é necessário aplicar um plano de recuperação da balaustrada a partir de uma manutenção corretiva.

A localização da balaustrada apresenta riscos de deteriorações causadas por terceiros devido à grande intensidade de veículos de pequeno a grande porte e pelo espaço das vias para movimentação destes.

De forma geral, afirma-se que o levantamento das principais manifestações patológicas na balaustradas correspondem a situação em que está inserida, com elevadas e constantes agressões do meio ambiente e ausência de manutenção preventiva. Para estudos futuros é necessário elaboração de um plano de recuperação de toda a balaustrada aplicando técnicas construtivas baseadas em uma manutenção corretiva, bem como ensaios de abordagem quantitativa e qualitativa para que se obtenha melhores classificações e detalhes sobre as circunstâncias da balaustrada. No caso dos balaústres, indica-se fazer a recuperação estrutural com materiais específicos e obedecendo as atuais diretrizes das normas pertinentes.

\section{REFERÊNCIAS}

ASSOCIAÇÃO BRASILEIRA DE NORMAS TÉCNICAS, NBR 6118: Projeto de estruturas de concreto Procedimento. Rio de Janeiro, 2014

ANDRADE, C. Manual para Diagnóstico de Obras Deterioradas por Corrosão de Armaduras. 25 p. Ed. Pini. 1992.

FARIAS, E. C. Avaliação da durabilidade frente ao ataque de CO2 e CI-em concretos autodensáveis com elevadores teores de resíduo da biomassa da cana-de-açúcar e metacaulim. Tese - Mestrado em Engenharia Civil. Programa de Pós-Graduação em Engenharia Civil. Universidade Federal do Rio Grande do Norte. Natal, 2019. Disponível em: <https://repositorio.ufrn.br/jspui/handle/123456789/27287>. Acesso em: 20 de setembro de 2019.

FIALHO, R. F; SEIBT, B. H; CARRIJO, S. A. Um estudo sobre a despassivação da armadura com ênfase na causada por carbonatação do concreto. In: IV Colóquio Estadual de Pesquisa Multidisciplinar \& II Congresso Nacional de Pesquisa Multidisciplinar, 2019. Anais. Mineiros, 2019. Disponível em: <http://publicacoes.unifimes.edu.br/index.php/coloquio/article/view/844>. Acesso em: 22 de setembro de 2019.

HELENE, P. R. L. Corrosão em armadura para concreto armado. p. 6. Instituto de Pesquisas Tecnológicas do Estado de São Paulo. 1986.

KULAKOWSKI, M. P. Contribuição ao estudo da carbonatação em concretos e argamassas compostos com adição de sílica ativa. Tese - Doutorado em Engenharia de Minas, Metalúrgica e Materiais, Programa de Pós-Graduação em Engenharia de Minas, Metalúrgica e Materiais. Universidade Federal do Rio Grande do Sul. Porto Alegre, 2002. Disponível em: <https://lume.ufrgs.br/handle/10183/3594>. Acesso em: 22 de setembro de 2019.

SOUZA, V. C. M; RIPPER, T. Patologia, recuperação e reforço de estruturas de concreto. Ed. Pini. 1998. 